\title{
The Time Decay of Bond Premium and Discount-An Analysis of the Time Passage Effect on Bond Prices
}

\author{
Jorge Brusa ${ }^{1}$, Jenny Gu ${ }^{2 *}$, Grace Yaru Liu ${ }^{3}$ \\ ${ }^{1}$ Division of International Banking \& Finance Studies, Sanchez School of Business, Texas A\&M International \\ University, Laredo, USA \\ ${ }^{2}$ College of Business, University of Dallas, Irving, USA \\ ${ }^{3}$ Department of Supply Chain and Information Systems, Pennsylvania State University, University Park, USA \\ Email: ibrusa@tamiu.edu, ${ }^{*}$ igu@udallas.edu, ygl100@psu.edu
}

Received 25 April 2014; revised 20 May 2014; accepted 30 May 2014

Copyright $@ 2014$ by authors and Scientific Research Publishing Inc.

This work is licensed under the Creative Commons Attribution International License (CC BY).

http://creativecommons.org/licenses/by/4.0/

(c) (1) Open Access

\begin{abstract}
In this paper, we show that the price of a premium bond and the price of a discount bond will both move toward face value at an increasing rate as the bonds approach maturity. We present a mathematical proof to show that the decline in premium and discount decline over time, to be referred to as time decay, accelerates as time passes by. We also provide numerical examples and graphical representations to illustrate the time passage effect on bond prices and discuss the implications of the findings to bond investor and asset managers in light of the quantitative easing policies taken by central banks after the 2008 financial crisis.
\end{abstract}

\section{Keywords}

Time Decay, Premium Bond, Discount Bond, Time Passage Effect, Quantitative Easing

\section{Introduction}

Researchers in economics and finance have studied the relationships among bond prices, interest rates, and maturity for many years. One of the best known results in the study is that, if the market interest rate on a bond remains unchanged, the price of a bond will approach its face value as the bond approaches maturity. However, how exactly and in what way the bond price approaches its face value has not been well discussed in textbooks. For example, when a bond is selling at premium (i.e. when the bond price is above its face value), the only way

${ }^{*}$ Corresponding author.

How to cite this paper: Brusa, J., Gu, J. and Liu, G.Y. (2014) The Time Decay of Bond Premium and Discount-An Analysis of the Time Passage Effect on Bond Prices. Theoretical Economics Letters, 4, 323-330.

http://dx.doi.org/10.4236/tel.2014.45043 
for the bond price to approach its face value is to move downward. Therefore the price path toward maturity for a premium bond must be downward-sloping. However, a downward-sloping path could be convex (decreasing at a decreasing rate), concave (decreasing at an increasing rate), or a straight line (decreasing at constant rate), to name just three. Similarly, when a bond is selling at discount (i.e. when the bond price is below its face value), the only way for the bond price to reach its face value is to move upward. Therefore the price path toward maturity for a discount bond must be upward-sloping. However, an upward-sloping path could also be convex (increasing at an increasing rate), concave (increasing at a decreasing rate), or a straight line (increasing at constant rate).

In this paper we formally present a mathematical proof to show that the price path for a premium bond is concave (decreasing toward the par at an increasing rate) and the price path for a discount bond is convex (increasing toward the par at an increasing rate) as the bond approaches maturity. In other words, we show that both the premium (defined as price minus the par) and the discount (defined as par minus the price) are diminishing at an increasing rate as the bond approaches maturity. This is the first contribution of our study because, to the best of our knowledge, no study in the literature has formally presented a mathematical proof to show that both the premium and the discount diminish at an increasing rate as bond approaches maturity ${ }^{1}$. Since both the premium and the discount will decrease over time when interest rate remains unchanged, we will refer to the decrease in premium and discount as time decay of premium and discount.

One of the reasons that most textbooks only briefly address the issue of bond price path toward maturity (e.g. Brigham and Houston, 2012) [1] and that some books do not even mention the issue (e.g. Booth, Cleary, and Drake, 2014; Gitman, Joehnk, Smart, 2011; Keown, Martin, and Petty, 2014) [2]-[4] may be that, in order to examine the time passage effect on bond price, the condition that the interest rate remains unchanged must hold. Some authors consider that condition too strong and therefore practically impossible ${ }^{2}$. It is true that interest rate may be constantly changing. However, the change in interest rate should not the reason to restrain us from examining the price change due to time passage. As Fabozzi (2007) [5] indicates, the change in bond price can always be decomposed into two components: one component due to time passage toward maturity without any change in interest rate, and one component due to the change in interest rate. In other words, regardless of whether interest rate changes or remains constant, there is always a component of change in bond prices due to time passage and that component should be thoroughly examined and fully understood ${ }^{3}$. This is the second reason that we thoroughly examine how time passage affects bond prices.

The results of this study should be interesting not only to scholars studying fixed income securities, but also to asset managers with clients holding bonds. As we show in Sections 2 and 3 in the paper, for premium bonds, their value decreases toward the par at an increasing rate over time. The quantitative easing policies initiated by the Federal Reserve, Bank of England, European Central Bank, and Bank of Japan as a response to the 2008 financial crisis have driven the global interest rates to historical lows. As a result, most bonds issued prior to 2008 (which usually carry coupon rates higher than the current interest rates), have become premium bonds in the past few years. As these bonds approach maturity, their prices will move lower over time even as the central banks continue to maintain the interest rate at the current level. Furthermore, since the prices of these premium bonds decrease at an increasing rate, the decrease in value for these bonds will accelerate as they approach maturity in the next few years. As many individual bond investors do not understand the time passage effect on bond prices, asset managers with clients investing in individual bonds or bond funds are likely to be questioned by their client as the clients see the value of their bonds declining at an increasing rate. The analyses of the bond

\footnotetext{
${ }^{1}$ We examined more than 30 textbooks in investments, financial management, and fixed income securities. The only textbook that briefly addresses the second derivative of the time path of bond prices — which is the major focus of our paper-is Sharpe, Alexander, and Bailey (1998) [6]. However, the book has not been in print since 1998. Also the book did not present a mathematical proof to examine the relationship between time passage and bond prices although it gave a numerical illustration. Since the book was published before the 2008 financial crisis, it did not address how the time passage effect on bond price may affect portfolio managers under the current central banks' quantitative easing $(\mathrm{QE})$ programs, which is another topic we address in our paper.

${ }^{2}$ For instance, one author starts the discussion of this issue by saying:

"Let's imagine a very unlikely event just to enhance our understanding of the process involved in bond pricing. What would happen to the price of the... bond as time goes by if interest rates didn't change again for the remainder of the bond's life (a practical impossibility)?” (Lasher 2014, p. 299) [7]

${ }^{3} \mathrm{~A}$ similar phenomenon can found in study of option pricing. Just as bond prices are affected by passage of time and market rate of interest, option prices are also affected by passage of time and the underlying asset price. Even though the underlying asset price is constantly changing just like the market rate of interest, how option prices are affected by the passage of time while holding the underlying asset price constant is very thoroughly studied and well understood in the option pricing theory. For the details of how option prices are affect by the passage of time, known as time decay of option prices, see Merton (1973) [8] and Smith (1976) [9].
} 
price path will provide to asset managers a tool to explain to their clients why the value of these bonds declines over time. This is the third reason for the study.

The rest of the paper is organized as follows. In Section 2, we present a mathematical proof to show how both the premium and the discount will decrease at an increasing rate as the bond approaches maturity. In Section 3, we present numerical examples to illustrate our findings. In Section 4 we discuss the implications of the findings in the paper. We conclude the paper in Section 5.

\section{Mathematical Model}

In this section, we will present a mathematical proof to show that the price of a premium bond will decline toward face value at an increasing rate over time, and the price of a discount bond will rise toward face value, also at an increasing rate as it approaches maturity.

The way we prove the arguments is as follows: we will first show that the price of a premium bond increases at a decreasing rate as the bond's term to maturity increases. However, in practice, a bond's term to maturity decreases over time. Consequently, as a bond approaches maturity, the price of a premium decreases at an increasing rate. Similarly, for a discount bond we will show that as term to maturity increases, the price decreases at a decreasing rate. Therefore, as the bond approaches the maturity and the term to maturity decreases, the price of a discount bond increases at an increasing rate.

We now formally present the mathematical proof:

Let $T$ be the term to maturity of the bond (and thus $T$ decreases when a bond moves toward maturity as time passes by), $c r$ be the coupon rate, $i$ be the market rate of interest, and $F$ be the face (par) value of the bond. Then the price of the bond, $P$, is determined by the equation:

$$
\begin{gathered}
P=c r \cdot F\left[\frac{1-\frac{1}{(1+i)^{T}}}{i}\right]+F\left[\frac{1}{(1+i)^{T}}\right] \\
P=\frac{c r \cdot F}{i}\left[1-\frac{1}{(1+i)^{T}}\right]+F\left[\frac{1}{(1+i)^{T}}\right] \\
\frac{\partial P}{\partial T}=\frac{c r \cdot F}{i}\left[(1+i)^{-T} \ln (1+i)\right]-F(1+i)^{-T} \ln (1+i) \\
\frac{\partial P}{\partial T}=\left[\frac{c r}{i}-1\right] F(1+i)^{-T} \ln (1+i) \\
\frac{\partial P}{\partial T}=0 \text { if }\left(\frac{c r}{i}-1\right)=0 \quad \text { (for a par bond where } c r=i \text { ) } \\
\frac{\partial P}{\partial T}>0 \text { if }\left(\frac{c r}{i}-1\right)>0 \quad \text { (for a premium bond where } c r>i \text { ) } \\
\frac{\partial P}{\partial T}<0 \text { if }\left(\frac{c r}{i}-1\right)<0 \quad \text { (for a discount bond where } c r<i \text { ) }
\end{gathered}
$$

Equation (3) shows that for a par bond, the price is a constant (equal to the par value), and the bond price path toward maturity for a par bond is a horizontal straight line.

Equation (4) shows that for a premium bond, the price is an increasing function of its term to maturity. As the bond approaches maturity, the term to maturity $T$ decreases. Consequently, the price for a premium bond decreases as it approaches maturity.

Equation (5) shows that for a discount bond, the price is a decreasing function of term to maturity. As a bond approaches maturity, the term to maturity $T$ decreases. As a result, the price for a discount bond increases as it approaches maturity. 
To find out whether the bond price path for a premium bond is decreasing at an increasing rate or at a decreasing rate, and whether the bond price path for a discount bond is increasing at an increasing rate or at a decreasing rate, we differentiate Equation (2) with respect to $T$ again and obtain:

$$
\begin{aligned}
& \frac{\partial^{2} P}{\partial T^{2}}=\left[\frac{c r}{i}-1\right] F \ln (1+i) \frac{\partial}{\partial T}\left[(1+i)^{-T}\right] \\
& \frac{\partial^{2} P}{\partial T^{2}}=\left[\frac{c r}{i}-1\right] F \ln (1+i)\left[-(1+i)^{-T} \ln (1+i)\right] \\
& \frac{\partial^{2} P}{\partial T^{2}}=-\left[\frac{c r}{i}-1\right] F[\ln (1+i)]^{2}(1+i)^{-T} \\
& \frac{\partial^{2} P}{\partial T^{2}}=0 \text { if }\left(\frac{c r}{i}-1\right)=0 \text { (for a par bond) } \\
& \frac{\partial^{2} P}{\partial T^{2}}<0 \text { if }\left(\frac{c r}{i}-1\right)>0 \text { (for a premium bond) } \\
& \frac{\partial^{2} P}{\partial T^{2}}>0 \text { if }\left(\frac{c r}{i}-1\right)<0 \text { (for a discount bond) }
\end{aligned}
$$

Combining Equations (4) and (7), the results show that the price for a premium bond is an increasing function with respect to $T$ at a decreasing rate. However, as a bond approaches maturity, the term to maturity $T$ decreases. Therefore, the price path for a premium bond toward maturity is decreasing at an increasing rate.

Equation (5) suggests that the price of a discount bond is a decreasing function of $T$. However, Equation (8) suggests that the downward-sloping curve becomes less negative as $T$ increases. Therefore Equations (5) and (8) suggest that the price for a discount bond is decreasing with respect to $T$ at a decreasing rate. However, as a bond approaches maturity, the term to maturity $T$ decreases. Therefore, the price path for a discount bond toward maturity is increasing at an increasing rate.

In the next section, we provide a few numerical examples and graphical representations to illustrate the mathematical proofs.

\section{Numerical Illustrations}

In Table 1 we present the prices for bonds with a face value of $\$ 1000$, five different coupon rates: $12 \%, 10 \%$, $8 \%, 6 \%$, and $4 \%$; and 21 different terms to maturity from 0 to 20 years. We assume the market rate of interest to be $8 \%$, and coupon payments are made annually.

In the table, we can observe the prices for premium bonds (bonds with coupon rates of $12 \%$ and $10 \%$ ) are increasing functions of term to maturity at a decreasing rate. For example, for the $12 \%$ bond the price increases by $\$ 37.04$ when term to maturity increases from 0 to 1 year, but the price increases by only $\$ 8.59$ when the term to maturity increases from 19 to 20 years. Since the price is increasing at a decreasing rate, it would not increase indefinitely as term to maturity approaches infinity. The price is equal to $P=\frac{c r \cdot F}{i}$ as $T$ approaches infinity (known as a perpetual bond) according to Equation (1), or $\$ 1500$ for a $12 \%$ bond when the market rate of interest is $8 \%$. Figure 1 is the graphical representation of Table 1 , showing bond prices as a function of term to maturity.

Since the price for a premium bond increases at a decreasing rate as term to maturity increases, the price path toward maturity date, which is the price movement with a decrease in term to maturity, is decreasing with an increasing rate.

Similarly, the prices for discount bonds (bonds with coupon rates of $6 \%$ and $4 \%$ ) are decreasing functions of term to maturity at a decreasing rate. For example, for the $4 \%$ bond the price decreases by $\$ 37.04$ when term to maturity increases from 0 to 1 year, but the price decreases by only $\$ 8.59$ when the term to maturity increases from 19 to 20 years. Since the price is decreasing at a decreasing rate, it does not decrease indefinitely as term to maturity approaches infinity. The price for a perpetual discount bond (with term to maturity approaches to in- 
Table 1. The prices for bonds with a face value of $\$ 1000$, coupon rates of $12 \%, 10 \%, 8 \%$, $6 \%$, and $4 \%$ respectively (assuming annual payment), and terms to maturity from 0 to 20 years when the market rate of interest is $8 \%$.

\begin{tabular}{|c|c|c|c|c|c|}
\hline \multirow[t]{2}{*}{ Term to Maturity } & \multicolumn{5}{|c|}{ Coupon Rate } \\
\hline & $12 \%$ & $10 \%$ & $8 \%$ & $6 \%$ & $4 \%$ \\
\hline 0 & $\$ 1000.00$ & $\$ 1000.00$ & $\$ 1000$ & $\$ 1000.00$ & $\$ 1000.00$ \\
\hline 1 & $\$ 1037.04$ & $\$ 1018.52$ & $\$ 1000$ & $\$ 981.48$ & $\$ 962.96$ \\
\hline 2 & $\$ 1071.33$ & $\$ 1035.67$ & $\$ 1000$ & $\$ 964.33$ & $\$ 928.67$ \\
\hline 3 & $\$ 1103.08$ & $\$ 1051.54$ & $\$ 1000$ & $\$ 948.46$ & $\$ 896.92$ \\
\hline 4 & $\$ 1132.49$ & $\$ 1066.24$ & $\$ 1000$ & $\$ 933.76$ & $\$ 867.51$ \\
\hline 5 & $\$ 1159.71$ & $\$ 1079.85$ & $\$ 1000$ & $\$ 920.15$ & $\$ 840.29$ \\
\hline 6 & $\$ 1184.92$ & $\$ 1092.46$ & $\$ 1000$ & $\$ 907.54$ & $\$ 815.08$ \\
\hline 7 & $\$ 1208.25$ & $\$ 1104.13$ & $\$ 1000$ & $\$ 895.87$ & $\$ 791.75$ \\
\hline 8 & $\$ 1229.87$ & $\$ 1114.93$ & $\$ 1000$ & $\$ 885.07$ & $\$ 770.13$ \\
\hline 9 & $\$ 1249.88$ & $\$ 1124.94$ & $\$ 1000$ & $\$ 875.06$ & $\$ 750.12$ \\
\hline 10 & $\$ 1268.40$ & $\$ 1134.20$ & $\$ 1000$ & $\$ 865.80$ & $\$ 731.60$ \\
\hline 11 & $\$ 1285.56$ & $\$ 1142.78$ & $\$ 1000$ & $\$ 857.22$ & $\$ 714.44$ \\
\hline 12 & $\$ 1301.44$ & $\$ 1150.72$ & $\$ 1000$ & $\$ 849.28$ & $\$ 698.56$ \\
\hline 13 & $\$ 1316.15$ & $\$ 1158.08$ & $\$ 1000$ & $\$ 841.92$ & $\$ 683.85$ \\
\hline 14 & $\$ 1329.77$ & $\$ 1164.88$ & $\$ 1000$ & $\$ 835.12$ & $\$ 670.23$ \\
\hline 15 & $\$ 1342.38$ & $\$ 1171.19$ & $\$ 1000$ & $\$ 828.81$ & $\$ 657.62$ \\
\hline 16 & $\$ 1354.05$ & $\$ 1177.03$ & $\$ 1000$ & $\$ 822.97$ & $\$ 645.95$ \\
\hline 17 & $\$ 1364.87$ & $\$ 1182.43$ & $\$ 1000$ & $\$ 817.57$ & $\$ 635.13$ \\
\hline 18 & $\$ 1374.88$ & $\$ 1187.44$ & $\$ 1000$ & $\$ 812.56$ & $\$ 625.12$ \\
\hline 19 & $\$ 1384.14$ & $\$ 1,192.07$ & $\$ 1000$ & $\$ 807.93$ & $\$ 615.86$ \\
\hline 20 & $\$ 1392.73$ & $\$ 1,196.36$ & $\$ 1000$ & $\$ 803.64$ & $\$ 607.27$ \\
\hline
\end{tabular}

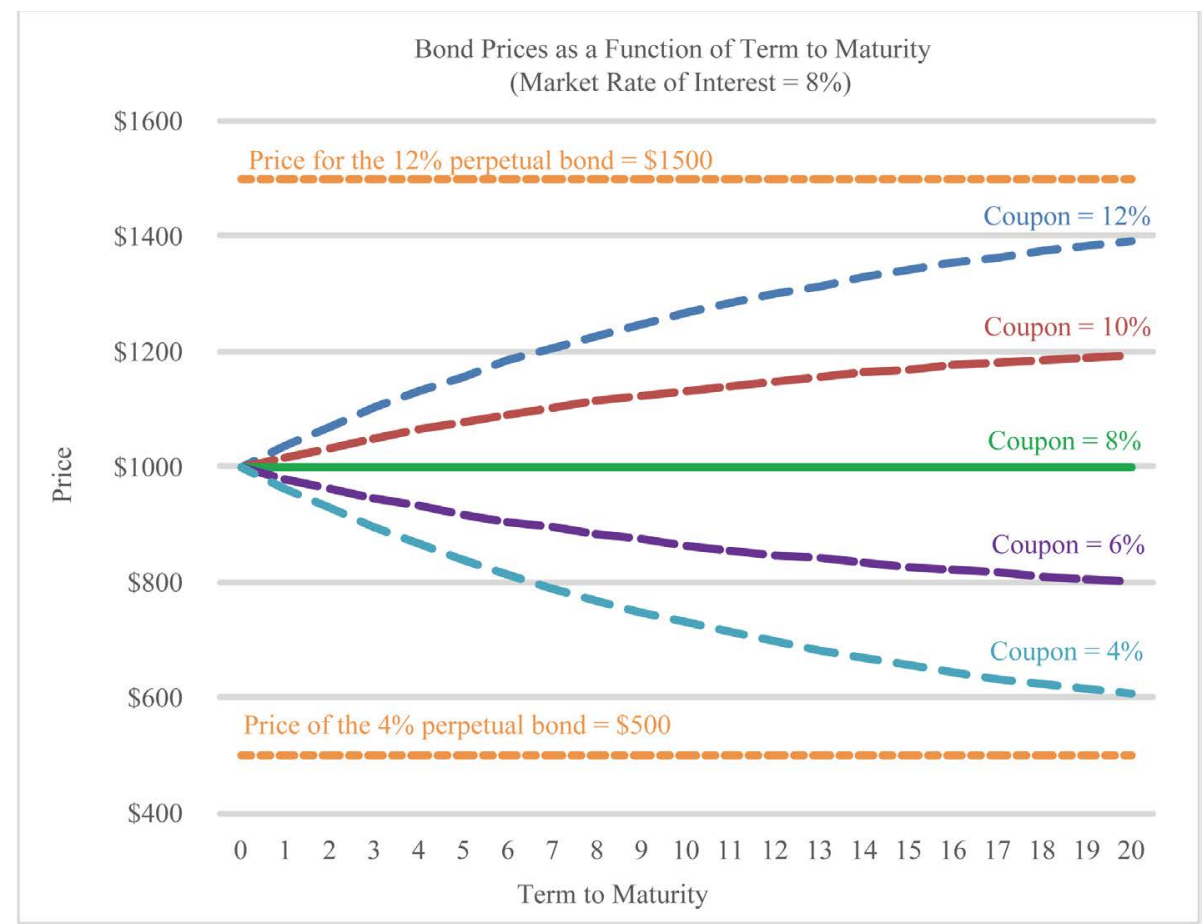

Figure 1. Bond prices as a function of term to maturity: the face value is $\$ 1000$, coupon rates are $12 \%, 10 \%, 8 \%, 6 \%$, and $4 \%$ respectively (assuming annual payment), and terms to maturity are from 0 to 20 years when the market rate of interest is $8 \%$. 
finity) is $P=\frac{c r \cdot F}{i}$, according to Equation (1), or $\$ 500$ for a $4 \%$ bond when the market rate of interest is $8 \%$.

Since the price for a discount bond decreases at a decreasing rate as term to maturity increases, the price path toward maturity date, which is the price movement with a decrease in term to maturity, is increasing with an increasing rate.

To enhance the understanding of the effect of time passage on bond prices, we construct Table 2 to illustrate how the prices of 20 -year bonds with different coupon rates converge toward face value as time approaches maturity date.

The results in Table 2 show that the price for the 10\% premium bond declines by $\$ 4.29$ from $\$ 1196.36$ to $\$ 1192.07$ in the first year after it is issued (from 20 years remaining until maturity to 19 years remaining until maturity). However, during the very last year immediately before maturity (from one year remaining until maturity to the maturity date), the price declines by $\$ 18.52$ from $\$ 1018.52$ to $\$ 1000$. The results show the price path toward maturity for a premium bond decreases at an increasing rate.

As the bond approaches maturity, the price approaches the face value and the premium (defined as the dollar amount above the face value) declines purely due to time passage without any change in interest rate, we refer to the decline as time decay in bond premium.

Similarly, the results in Table 2 show that, the price for the $6 \%$ premium bond rises by $\$ 4.29$ from $\$ 803.64$ to $\$ 807.93$ in the first year after it is issued (from 20 years remaining until maturity to 19 years remaining until maturity). However, during the very last year right before maturity (from one year remaining until maturity to the maturity date), the price rises by $\$ 18.52$ from $\$ 981.48$ to $\$ 1000$. The results show the price path toward maturity for a discount bond rises at an increasing rate.

Table 2. The convergence of bond prices toward face value as they approaches maturity date. The bonds have coupon rates of $12 \%, 10 \%, 8 \%, 6 \%$, and $4 \%$ respectively and a face value of $\$ 1000$. We assume all the bonds start with an initial term to maturity of 20 years, the market rate of interest is $8 \%$, and interests are paid annually.

\begin{tabular}{|c|c|c|c|c|c|}
\hline \multirow{2}{*}{$\begin{array}{l}\text { Term Remaining } \\
\text { Until Maturity }\end{array}$} & \multicolumn{5}{|c|}{ Coupon Rate } \\
\hline & $12 \%$ & $10 \%$ & $8 \%$ & $6 \%$ & $4 \%$ \\
\hline 20 & $\$ 1392.73$ & $\$ 1196.36$ & $\$ 1000$ & $\$ 803.64$ & $\$ 607.27$ \\
\hline 19 & $\$ 1384.14$ & $\$ 1192.07$ & $\$ 1000$ & $\$ 807.93$ & $\$ 615.86$ \\
\hline 18 & $\$ 1374.88$ & $\$ 1187.44$ & $\$ 1000$ & $\$ 812.56$ & $\$ 625.12$ \\
\hline 17 & $\$ 1364.87$ & $\$ 1182.43$ & $\$ 1000$ & $\$ 817.57$ & $\$ 635.13$ \\
\hline 16 & $\$ 1354.05$ & $\$ 1177.03$ & $\$ 1000$ & $\$ 822.97$ & $\$ 645.95$ \\
\hline 15 & $\$ 1342.38$ & $\$ 1171.19$ & $\$ 1000$ & $\$ 828.81$ & $\$ 657.62$ \\
\hline 14 & $\$ 1329.77$ & $\$ 1164.88$ & $\$ 1000$ & $\$ 835.12$ & $\$ 670.23$ \\
\hline 13 & \$1316.15 & $\$ 1158.08$ & $\$ 1000$ & $\$ 841.92$ & $\$ 683.85$ \\
\hline 12 & $\$ 1301.44$ & $\$ 1150.72$ & $\$ 1000$ & $\$ 849.28$ & $\$ 698.56$ \\
\hline 11 & $\$ 1285.56$ & $\$ 1142.78$ & $\$ 1000$ & $\$ 857.22$ & $\$ 714.44$ \\
\hline 10 & $\$ 1268.40$ & $\$ 1134.20$ & $\$ 1000$ & $\$ 865.80$ & $\$ 731.60$ \\
\hline 9 & $\$ 1249.88$ & $\$ 1124.94$ & $\$ 1000$ & $\$ 875.06$ & $\$ 750.12$ \\
\hline 8 & $\$ 1229.87$ & $\$ 1114.93$ & $\$ 1000$ & $\$ 885.07$ & $\$ 770.13$ \\
\hline 7 & $\$ 1208.25$ & $\$ 1104.13$ & $\$ 1000$ & $\$ 895.87$ & $\$ 791.75$ \\
\hline 6 & $\$ 1184.92$ & $\$ 1092.46$ & $\$ 1000$ & $\$ 907.54$ & $\$ 815.08$ \\
\hline 5 & $\$ 1159.71$ & $\$ 1079.85$ & $\$ 1000$ & $\$ 920.15$ & $\$ 840.29$ \\
\hline 4 & $\$ 1132.49$ & $\$ 1066.24$ & $\$ 1000$ & $\$ 933.76$ & $\$ 867.51$ \\
\hline 3 & $\$ 1103.08$ & $\$ 1051.54$ & $\$ 1000$ & $\$ 948.46$ & $\$ 896.92$ \\
\hline 2 & $\$ 1071.33$ & $\$ 1035.67$ & $\$ 1000$ & $\$ 964.33$ & $\$ 928.67$ \\
\hline 1 & $\$ 1037.04$ & $\$ 1018.52$ & $\$ 1000$ & $\$ 981.48$ & $\$ 962.96$ \\
\hline 0 & $\$ 1000.00$ & $\$ 1000.00$ & $\$ 1000$ & $\$ 1000.00$ & $\$ 1000.00$ \\
\hline
\end{tabular}


As the bond approaches maturity, the price approaches the face value and the discount (defined as the dollar amount below the face value) declines purely due to time passage without any change in interest rate, we refer to the decline as time decay in bond discount.

Figure 2 is the graphical representation of Table 2 showing the price path of bonds with different coupon rates as these bonds approach maturity when all the bonds start with an initial term to maturity of 20 years. Note that the bond prices in Figure 1 and the bond prices in Figure 2 are symmetric with respect to the y-axis as the $\mathrm{x}$-axis in Figure 1 is the term to maturity (number of years in ascending order) while the $\mathrm{x}$-axis in Figure 2 is the term remaining until maturity (number of years in descending order).

\section{Implications of the Findings}

The findings in the paper in and by itself are interesting and important. As we discussed, the change in bond prices can always be decomposed into at least two components: one component due to time passage without taking into account the change in interest rate, and one component due to the change in interest rate. To fully understand bond pricing, it is necessary to understand the driving forces behind both components. The findings in this paper contribute to the understanding of the first component.

Moreover, the findings in the paper can also enhance the management of fixed income securities and the communication between asset managers and their clients. As we have shown in the paper, the value of premium bonds declines at an increasing rate as they approach maturity. To respond to the 2008 financial crisis, central banks worldwide have taken programs in the past few years. These programs have driven interest rates to historical lows and many bonds issued before 2008 (which carry coupon rates higher than the current interest rates) have become premium bonds. As these bonds approach maturity in the next few years, their value will decline. Moreover, because the price of premium bonds declines at an increasing rate, the decline of these bonds' value will accelerate even central banks maintain the current policy unchanged. As most investors do not fully understand the time decay of bond premium, they may unfairly blame asset managers for the decline in bond value even the decline is purely due to the passage of time and the central banks' monetary policies. A better understanding of the price path effect on bond prices will help asset managers manage bond portfolios more effectively and enhance the communications between asset manager and their clients.

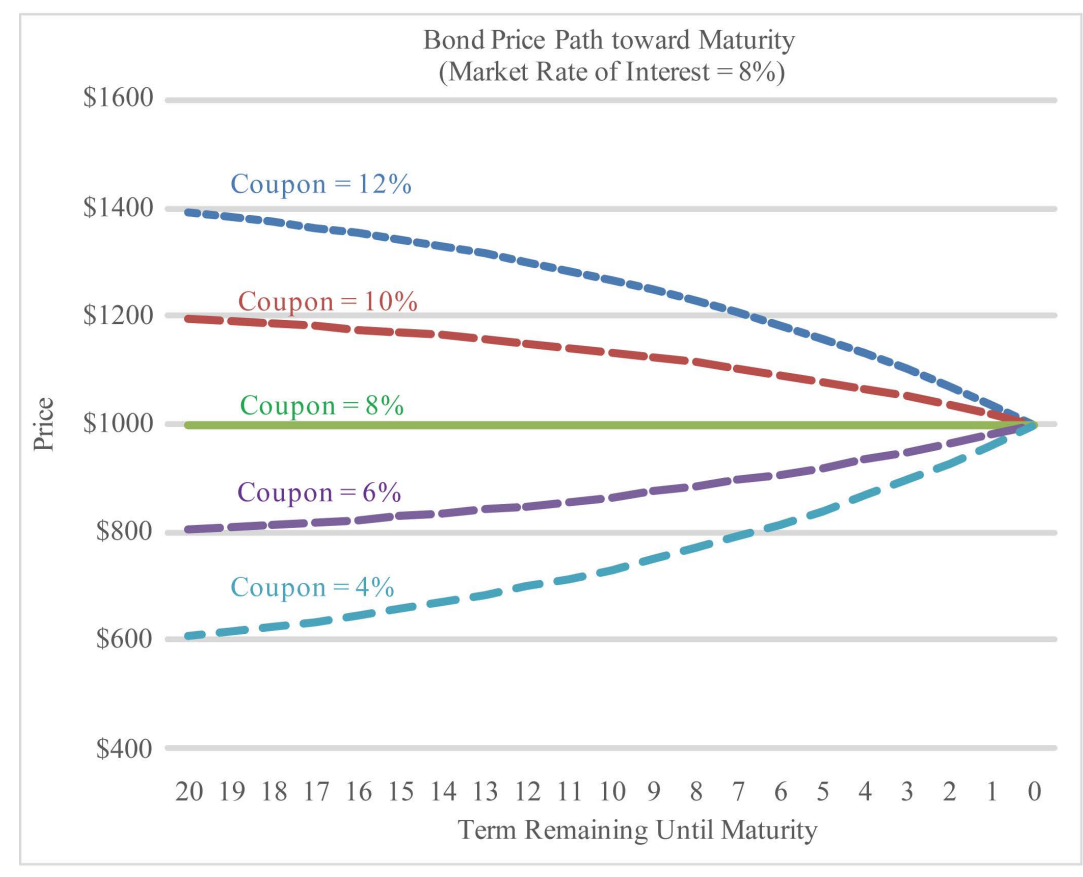

Figure 2. Bond prices as a function of term remaining until maturity: the face value is $\$ 1000$, coupon rates are $12 \%, 10 \%, 8 \%, 6 \%$, and $4 \%$ respectively (assuming annual payment), and all the bonds start with an initial term to maturity of 20 years when the market rate of interest is $8 \%$. 


\section{Conclusion}

In this paper, we show that as bonds approach maturity, the price of a premium bond will decline to the face value at an increasing rate, and the price of a discount bond will rise to the face value at an increasing rate. As both the prices of premium and discount bonds move toward face value, the premium and the discount will decrease over time even when interest rate remains unchanged. We refer to the decrease purely caused by time passage as time decay in premium and discount. We present a mathematical proof to show that the time decay accelerates over time. We also provide numerical examples and graphical representations to illustrate the time passage effect on bond prices. Finally we discuss the implications of the findings to bond investors and asset managers.

\section{References}

[1] Brigham, E. and Houston, J. (2012) Fundamentals of Financial Management. 7th Edition, South-Western Cengage, Boston.

[2] Booth, L., Cleary, S. and Drake, P. (2014) Corporate Finance. John Wiley \& Sons, Hoboken.

[3] Gitman, L., Joehnk, M. and Smart, S. (2011) Fundamentals of Investing. 11th Edition, Prentice Hall, Upper Saddle River.

[4] Keown, A., Martin, J. and Petty, W. (2014) Foundation of Finance. 8th Edition, Pearson, London.

[5] Fabozzi, F. (2007) Fixed Income Analysis. 2nd Edition, Wiley, Hoboken.

[6] Sharpe, W., Alexander, G. and Bailey, J. (1998) Investments. 6th Edition, Prentice Hall, Upper Saddle River.

[7] Lasher, W. (2014) Practical Financial Management. 7th Edition, Cengage Learning, Boston.

[8] Merton, R. (1973) Theory of Rational Option Pricing. The Bell Journal of Economics and Management Science, 4, 141-183. http://dx.doi.org/10.2307/3003143

[9] Smith, C. (1976) Option Pricing: A Review. Journal of Financial Economics, 3, 3-51. http://dx.doi.org/10.1016/0304-405X(76)90019-2 